\title{
Immunoreactive Metallothionein in Salivary Gland Neoplasms
}

\author{
Prashanta Shrestha, Hisashi Takagi, Yoshiaki Takai, Keiji Suzuki* and Masahiko \\ Mori
}

Department of Oral and Maxillofacial Surgery, Asahi University School of Dentistry, Gifu 501-02 and

*School of Medicine, Department of Pathology, College of Medical Care and Technology,

Gunma University, Maebashi, Gunma 371

Received for publication January 24, 1996 and in revised form March 1, 1996

\begin{abstract}
Metallothionein (MT), a low molecular weight intracellular protein present in cytoplasm and nucleus, possesses a selective binding affinity for zinc, copper and other group II heavy metal ions which may have a potential role to bind, sequester or detoxify these metal ions and alter the treatment response to chemotherapy or radiotherapy. The present study describes expression of MT in normal salivary glands and neoplastic salivary lesions using immunohistochemical method. Immunoreactive MT in normal salivary glands was observed in ductal cells where the immunostaining was most prominent in ductal basal cells of excretory and striated ducts and intercalated duct cells. Expression of MT was also observed in various salivary tumors; pleomorphic adenoma had immunoreactive MT in fibrillar and plasmacytoid neoplastic myoepithelial cells and chondroid cells

whereas Warthin's tumor, monomorphic adenoma and adenoid cystic carcinoma had non-luminal or basally located tumor cells intensely reactive. Acinic cell carcinoma cells were weakly reactive, however, papillary cystadenocarcinoma had a mixed population of cells with majority of the tumor cells moderately, and few cells strongly reactive. The profile of distribution of MT in salivary gland tumors was similar to that for S100 proteins suggesting their coexpression. The result of the present study suggests that MT is expressed in normal salivary glands. In various salivary gland tumors, in spite of histopathological heterogeneity, differentiation, binding potential and sequestration or detoxification of toxic metal ions by MT may confer a heterogeneous biological behavior. They also respond to the therapeutic modality of radiation and chemotherapy.
\end{abstract}

Key words: Immunohistochemistry, Metallothionein, Salivary gland tumors

\section{Introduction}

Metallothionein (MT) is low-molecular weight intracellular protein having a selective binding affinity for zinc, copper and other group II heavy metal ions. The synthesis of MT, classified as type I (MT-1) and type II (MT-2), is induced in a variety of tissues by these metal ions and by endogeneous factors such as glucocorticoids, interferons, interleukin-1 and vitamin D3 (for review, see Nath et al, 1988) [20].

The observation of high levels of MT [23, 24] and MTmRNA [1] in fetal and neonatal livers, similar to alpha-feto protein, but at a very low concentration in the

Correspondence to: Professor Masahiko Mori, Department of Oral and Maxillofacial Surgery, Asahi University School of Dentistry, 1851 Hozumi, Motosu-gun, Gifu 501-02, Japan. adult mammalian liver resulted in studies to evaluate the presence of MT in normal and neoplastic tissues. Since MT have the ability to bind with a large quantity of metal ions, their functional role has been implicated as an intracellular reservoir or sequestration for essential or potentially toxic metals ions such as Zinc and copper, respectively. MT have been found to play a significant role in the detoxification of toxic metals such as cadmium and possibly may have a role in the cellular protection against ionizing radiation and alkylating agents $[3,35]$. Furthermore, increased expression of MT has been associated with drug resistance by cancer cell lines and decreased cytotoxic activity of chemotherapeutic agents and increased resistance to ionizing radiation have been documented in MT-rich cells $[12,14,33]$. The sequestration of drugs or their metabolites by MT may prevent the reaction of the potentially toxic agents with the respective intracellular 
targets, and scavenging free radicals may contribute to the chemo- and radio-protective effects of MT in various neoplastic lesions.

The present study describes the expression of MT in normal salivary gland and a series of different types of salivary neoplasms using polyclonal antibody specifically recognizing epitopes of type I and type II MT.

\section{Materials and Methods}

Surgically resected specimens of normal salivary gland tissue $(\mathrm{n}=10)$ and salivary neoplasms from patients without a history of preoperative chemo or radiotherapy (pleomorphic adenoma, $\mathrm{n}=15$; monomorphic adenoma, $\mathrm{n}=5$; Warthin's tumor, $\mathrm{n}=15$; salivary gland papilloma, $\mathrm{n}=1$; adenoid cystic carcinoma, $\mathrm{n}=5$; acinic cell carcinoma, $n=5$; clear cell carcinoma, $n=4$ ) were studied. The specimens were routinely fixed in 10\% neutral buffered formalin for 6-12 hr and embedded in paraffin. Serial sections $(4 \mu \mathrm{m})$ were used for HE staining to evaluate the histopathological characteristics and immunostaining for MT using a three stage streptavidin biotin immunoperoxidase method. In brief, after blocking of the endogeneous peroxidase activity, the non- specific background staining was blocked by normal goat serum $(1: 20$ for $30 \mathrm{~min})$ and the sections were treated with primary anti-MT antibody, $1: 500,1 \mathrm{hr}$, room temperature. The antibody has been found to react with MT-1 and MT-2 and the specificity of the staining reaction has been confirmed in prior absorption of MT antibody with pure rabbit liver MT (MT-1 and MT-2; Sigma Chem. Co., St Louis, MO, USA [13, 18, 30, 31]. Subsequently, biotinylated goat anti-rabbit $\operatorname{IgG}(1: 200$, $30 \mathrm{~min})$ and streptavidin biotin complex $(1: 500$, $30 \mathrm{~min}$ ), obtained from Dako, Denmark, were applied. Finally the reaction products were visualized by $0.02 \% 3$ 3 'diaminobenzidine hydrochloride (DAB) containing $0.005 \% \mathrm{H}_{2} \mathrm{O}_{2}$ for $2-5 \mathrm{~min}$.

Sections of breast carcinoma were taken as positive control and primary antibody substituted by PBS or preimmunized rabbit serum at the same dilution of primary antiserum was used as negative control.

\section{Results}

Immunoreactivity of MT was observed either in the nuclei or cytoplasm or both and the following sections describe the selective localization in normal salivary gland

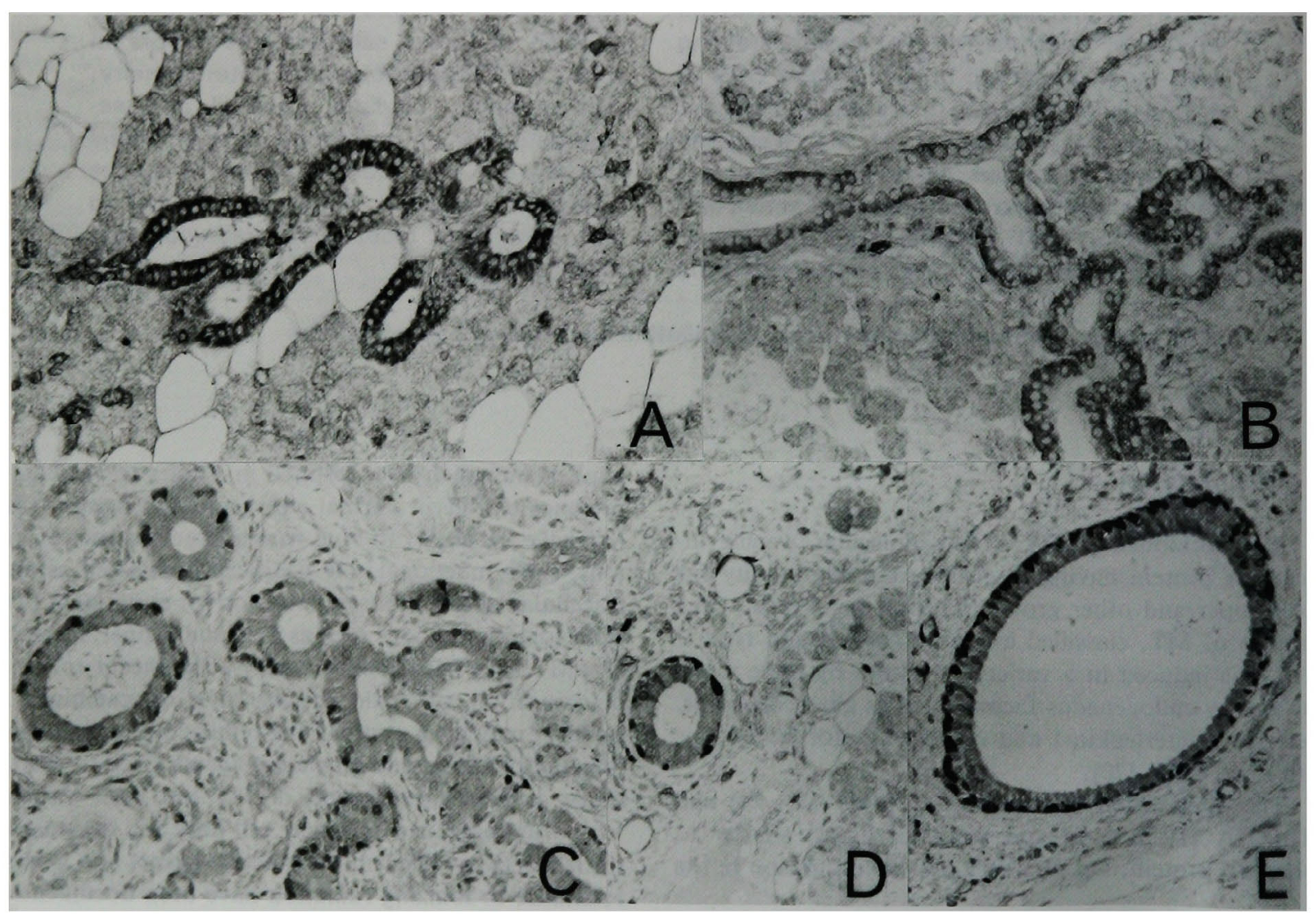

Fig. 1. Normal salivary glands. $\times 100$. A: Striated and intercalated ducts in parotid gland show an intense immunostaining. No staining is seen in the myoepithelial cells. B: The basal aspects of striated and excretory duct cells in submandibular gland show immunostaining. C, D \& E: Immunoreactive MT is seen in the ductal basal cells of striated and excretory ducts. 
and various salivary tumors.

\section{Normal salivary glands}

Immunoreactive MT was localized in the ductal segments of salivary glands which included intercalated, striated and excretory ducts (Fig. 1-A, B, C, D, E). Most conspicuous staining was observed in the ductal basal cells of striated and excretory ducts (Fig. 1-C, D, E). The myoepithelial cells, serous and mucous acini were unreactive.

\section{Pleomorphic adenoma}

Histologically, pleomorphic adenoma showed numerous tubulo-ductal structures with lumina lined by a single layer of luminal cells surrounded by non-luminal or neoplastic myoepithelial cells. Numerous non-luminal tumor cells forming small ducts or small nests in irregular patterns showed an intense reaction for MT (Fig. 2-A, B). The non-luminal cells were the predominant cells in expressing MT in pleomorphic adenoma (Fig. 2-C, D). The fibrillary or spindle-shaped neoplastic myoepithelial cells (Fig. 3A) in myxoid or hyalinous areas had MT either in the nuclei or in cytoplasm or both and the immunostaining was most conspicuous in the neoplastic myoepithelial cell which were relatively larger in size. (Fig. 3-B, C). The chondroid cells in the tumor had either nuclear or cytoplasmic staining for MT (Fig. 3-D, E).

\section{Monomorphic adenoma}

The tumor showed a uniform cellular architecture forming tubules with lumens lined by two layers of cells, the luminal and non-luminal cells (Fig. 4A) where only the

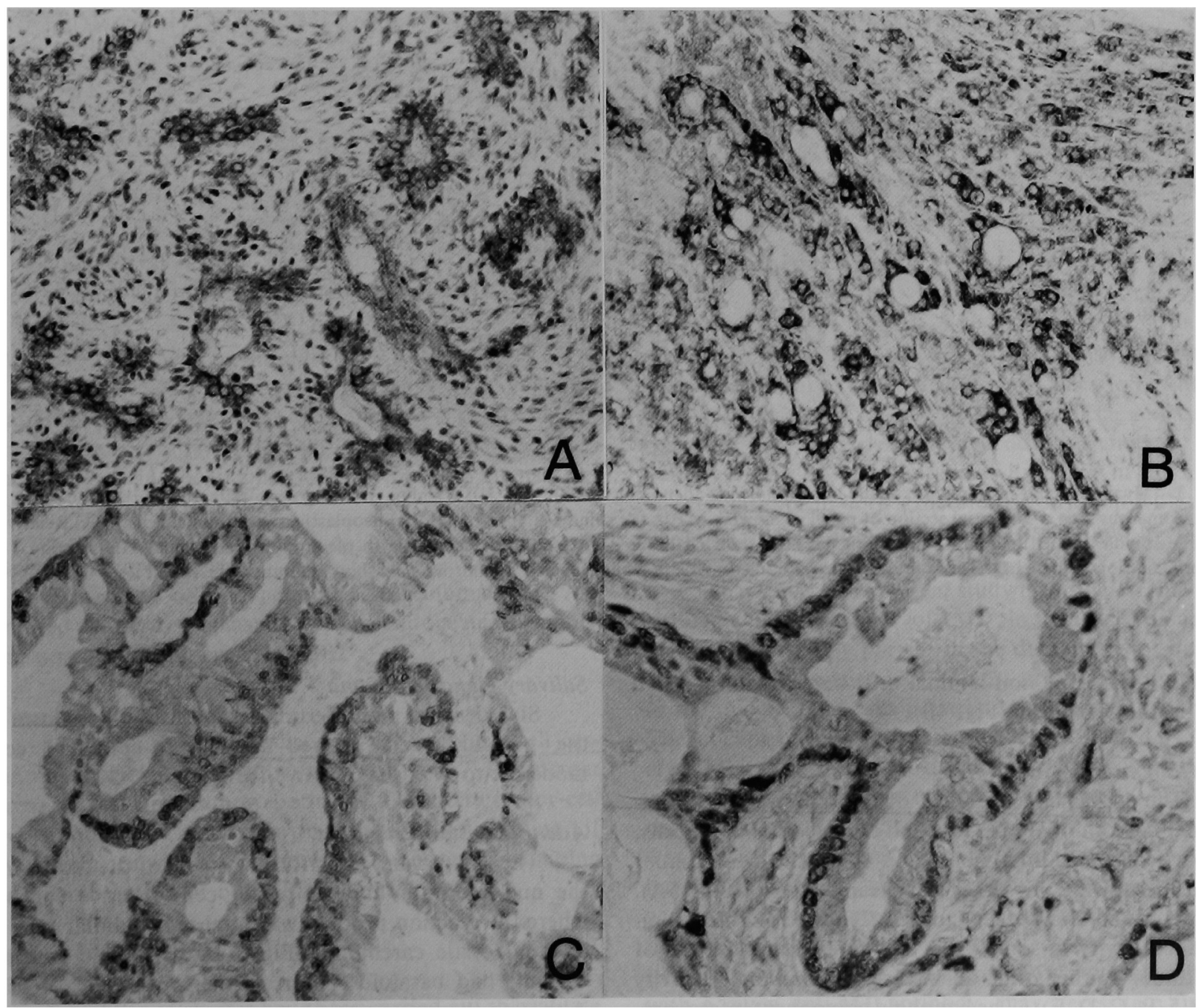

Fig. 2. Pleomorphic adenoma. A: Pleomorphic adenoma, histologically, shows tumor cells forming tubular or duct like structures containing luminal and non-luminal cells. Cells surrounding the duct-like structures show immunostaining for MT. $\times 100$. B: Non-luminal cells of larger tubulo-duct like structures show immunoreactive MT. $\times 100$. C: Immunostaining for MT is seen in the cytoplasm of non-luminal tumor cells (neoplastic myoepithelial cells). $\times 200$. D: The non-luminal cells of the tubulo-ductal structures show immunoreactive MT in the nuclei. $\times 200$. 


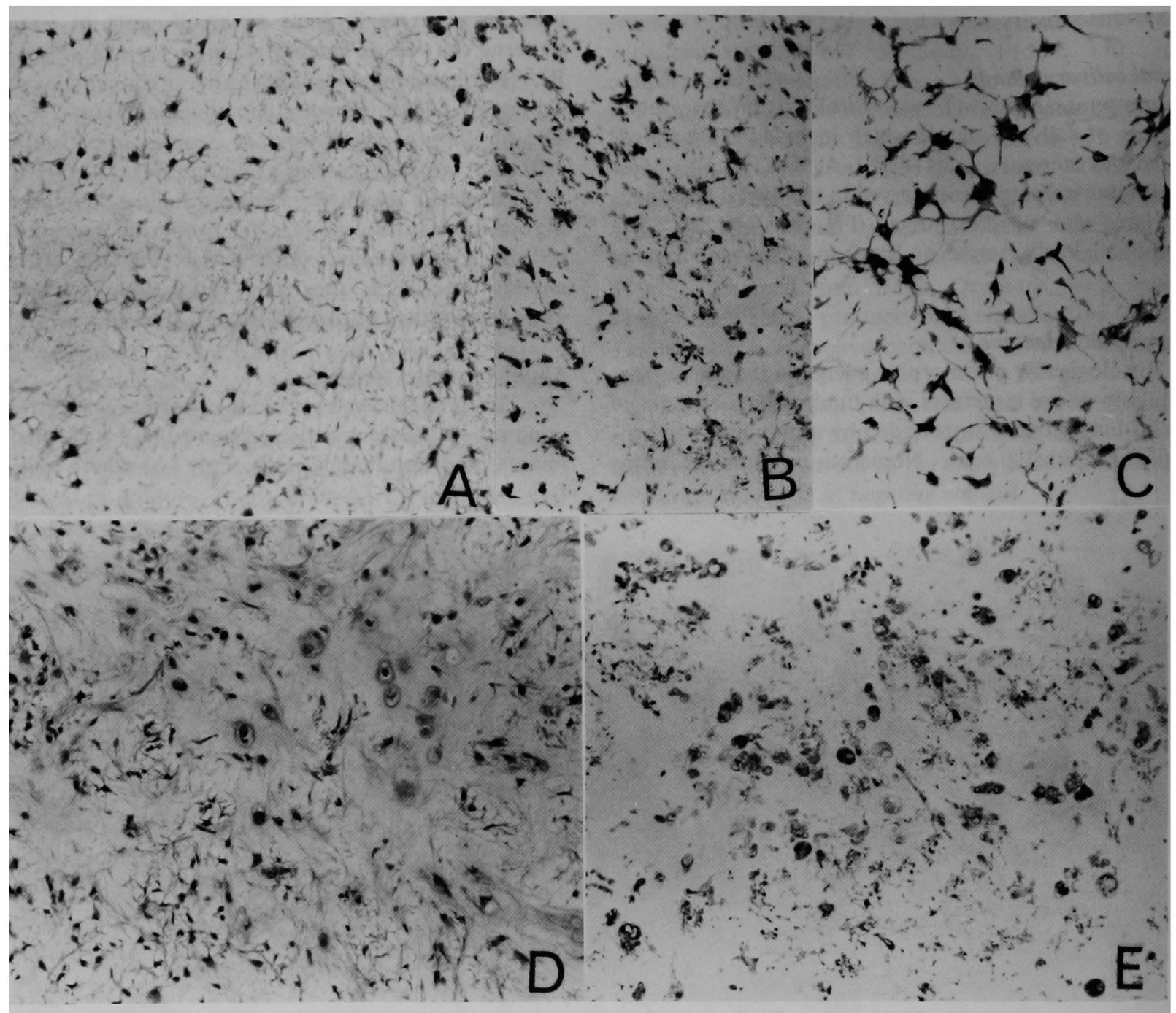

Fig. 3. Hyalinous and myxomatous tissue in pleomorphic adenoma. $\times 100$. A: HE staining, showing neoplastic myoepithelial cells in the myxomatous area. B: Serial section of panel A showing MT in the spindle-shaped (dendritic) neoplastic myoepithelial cells. C: Relatively large spindle shaped neoplastic myoepithelial cells showing MT. D: Chondroid metaplasia in pleomorphic adenoma, HE staining. E: Serial section of panel $\mathbf{D}$, The spindle shaped modified myoepithelial cells and chondroid cells show immunoreactive MT.

basally located or non-luminal cells had immunoreactive MT in the cytoplasm (Fig. 4B).

\section{Warthin's tumor}

The epithelial component of the tumor showing columnar cells lining the lumens and the cuboidal basal cells, in particular, had immunoreactive MT in the cytoplasm of basal cells with or without nuclear staining (Fig. 5A). Numerous columnar cells, however, showed an intense immunoreactivity in some areas and rarely basal aspects of the tumor epithelia had an intense MT immunoreactivity (Fig. 5-B, C, D, E). The lymphoid component infrequently had MT immunostaining (Fig. 5B), however, spindle shaped long anastomosing cells in the stroma (Fig. 5F) showed an intense immunoreactivity.

\section{Salivary gland papilloma}

Sialadenoma papilliferum, a rare benign neoplasm of the parotid gland showed neoplastic epithelial cells moderate to intensely reactive for MT (Fig. 5G).

\section{Adenoid cystic carcinoma}

The tubular and cribriform variants of the tumor had the nuclei of non-luminal tumor cells reactive for MT where the reaction product was intense in tubular type of adenoid cystic carcinoma (Fig. 6-A, B). The basaloid variants had basaloid tumor cell nests reactive for MT. Although there was a weak cytoplasmic staining, nuclear staining for MT was most prominent in this group of neoplasm. 


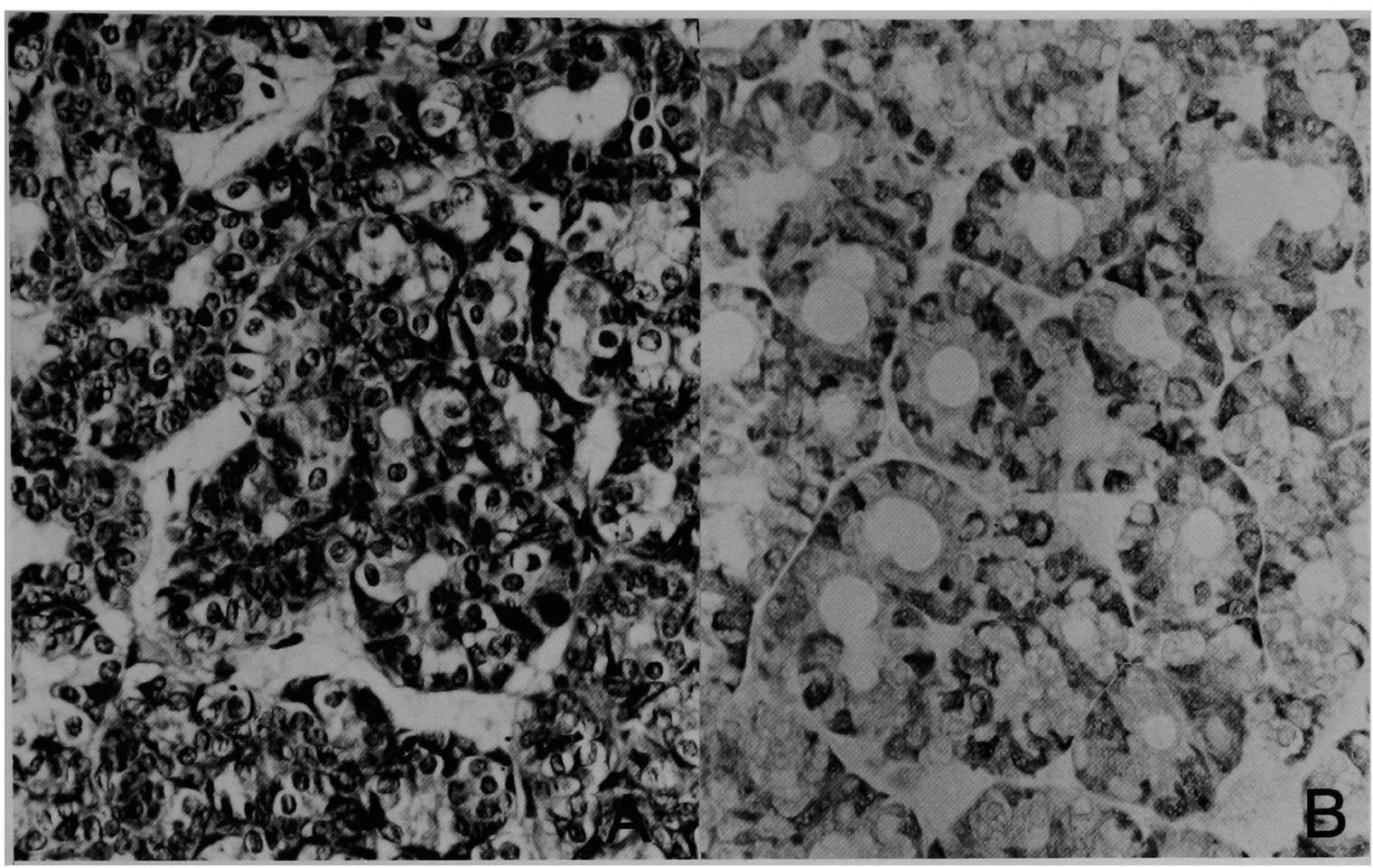

Fig. 4. Monomorphic adenoma $\times 200$. A: Histologically, monomorphic adenoma shows a uniform tumor cell architecture comprising tubular structures lined by a double cell layer, the luminal and non-luminal cells, HE staining. B: Immunostaining for MT is seen in the nonluminal tumor cells.

\section{Papillary cystadenocarcinoma}

This rare parotid neoplasm showed tumor cells in papillary arrangement (Fig. 6C) and MT staining was in traces in the majority of the tumor cells, however, few cells intermingled in the papillary focus had an intense immunoreactivity (Fig. 6D).

\section{Acinic cell carcinoma}

The tumor cells in acinic cell carcinoma (Fig. 7A) showed a diffuse cytoplasmic staining and the nuclear staining was not prominent (Fig. 7B).

\section{Clear cell carcinoma}

MT immunoreactivity in clear cells of clear cell carcinoma had a heterogeneous reaction pattern. In different areas of the same tumor specimen, there were tumor cell nuclei intensely reactive with weak or no staining of cytoplasm or cytoplasmic staining without nuclear staining or a combination of both (Fig. 7-C, D).

\section{Discussion}

A number of studies have been carried out to evaluate MT in human tissues such as liver, kidney, lungs, intestine, prostrate, testis, breast, brain and in various human neoplasia $[2,4-6,11,18,19,21,25,26,29,34]$. The only study in salivary glands by Oord et al, using frozen tissue specimens, has shown MT in salivary tissues [22]. The present study describes selective localization of MT in normal salivary gland and their neoplastic lesions using routinely processed paraffin embedded specimens. Our observation of MT immunoreactivity either in the nuclei or cytoplasm or in both structures is consistent with those of earlier studies in normal human tissues and neoplastic lesions.

The results of the present study may suggest that MT, although biologic role of MT in salivary tissues is unknown, is mainly present in the ductal cells of normal human salivary glands with a most prominent expression in the ductal basal cells of striated and excretory ducts. The labeling of myoepithelial cells, demonstrated by Oord et al [22] in frozen sections of salivary tissues, could not be observed in our paraffin embedded specimens, however, the pattern of labeling of the ductal basal cells in our series was consistent with their observation of labeling of ductal basal cells which has been described as reserve cells in the genesis of salivary tumors. This inconsistency in labeling of normal salivary tissue, if attributed to a difference in tissue processing or on epitopes of MT molecule binding with a given anti-MT antibody, may necessitate further evaluation to conclude MT as a marker of salivary myoepithelial cells. The labeling of myoepithelial cells and ductal basal cells by anti-MT antibody neither substantiate nor segregate these cells as reserve cells in the genesis 


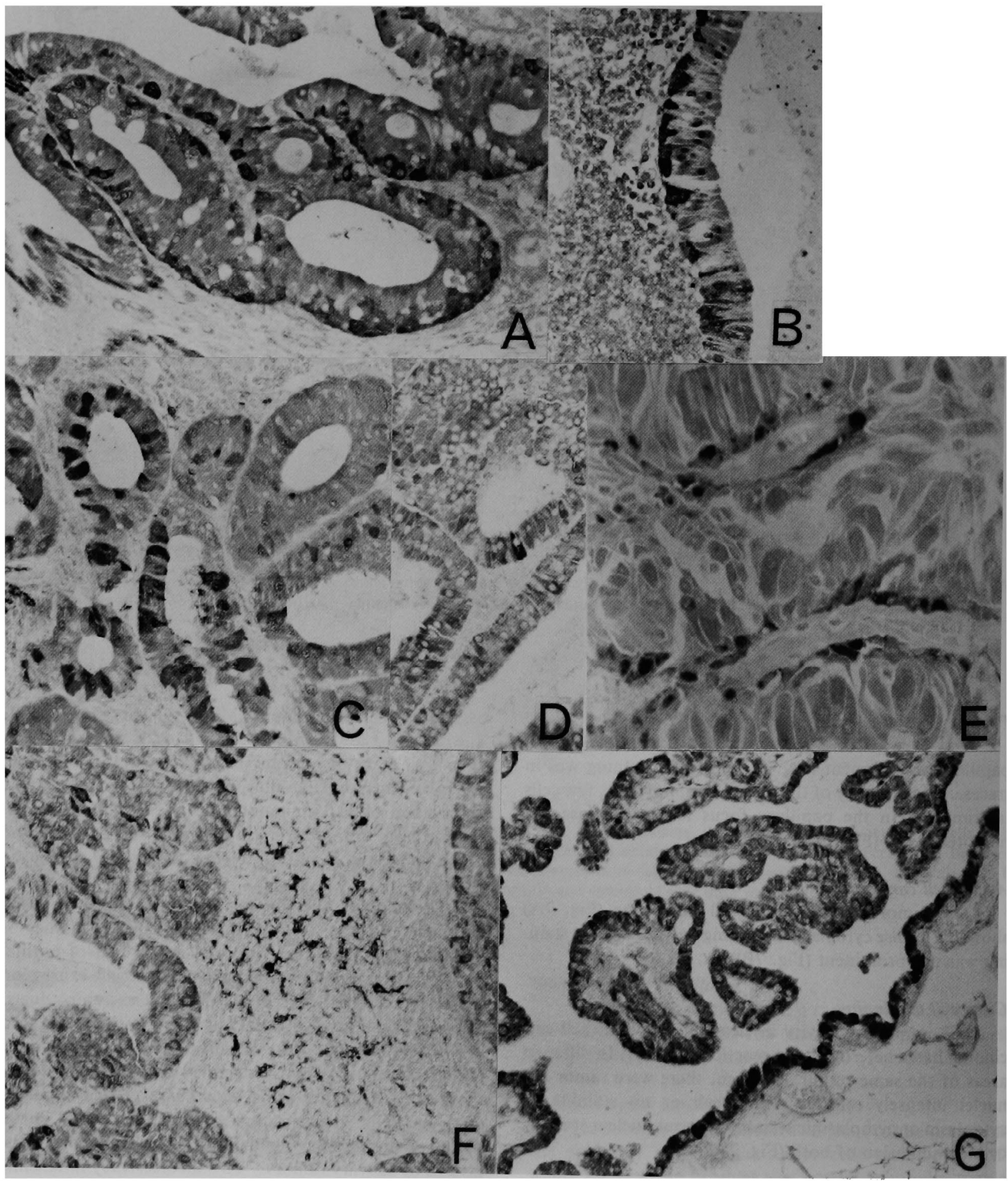

Fig. 5. Warthin's tumor and parotid gland papilloma. A: Warthin's tumor shows epithelial and lymphoid cells where the former contain a double cell layer with tall columnar cells and cuboidal basal cells. The basal cells are the predominant cells with immunoreactive MT in this case. $\times 100$. B: In numerous instances, in different areas of the same tumor specimen, in addition to the basal cells, the nuclei of tall columnar cells and lymphoid cells also show immunoreactive MT. $\times 100$. C \& D: The columnar cells are the predominant cells with MT in this case. $\times 100$. E: The nuclei of the basally located flattened cuboidal cells show immunoreactive MT. $\times 200$. F: Lymphoid stroma of Warthin's tumor containing dendritic cells with immunoreactive MT. $\times 100$. G: Parotid gland papilloma: The epithelial cells of the papilloma show intense immunoreaction for MT. $\times 100$. 


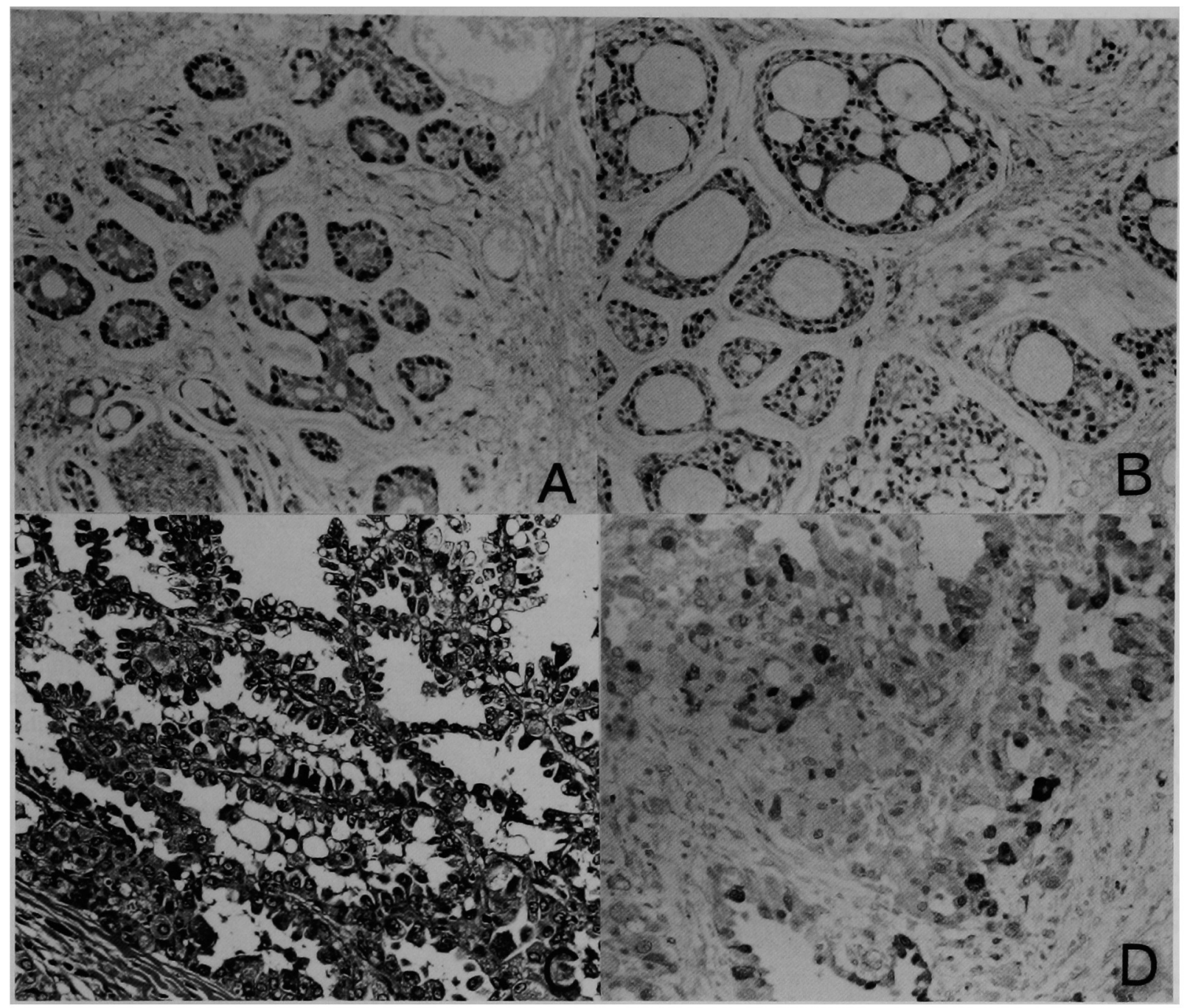

Fig. 6. Adenoid cystic carcinoma and papillary cystadenoma of parotid gland. $\times 100 . \quad$ A \& B: The tumor cell nuclei in adenoid cystic carcinoma show immunoreactive MT. C: Papillary cystadenocarcinoma. HE staining showing tumor cells in papillary projections. D: Except for few intensely reactive tumor cells, majority of the cells do not show reaction products for MT.

of salivary tumors as suggested by Oord et al [22]. Schmid et al [26] and Suzuki et al [29] have described nonneoplastic and neoplastic myoepithelial cells having immunoreactive MT in normal breast and its benign and malignant tumors. In addition, the myoepithelial cells in human breast, reported to be reactive for MT, may not necessarily represent the expression of MT in salivary myoepithelial cells which are structurally and functionally more heterogeneous.

A consistent reactivity of MT in salivary tumors in non-luminal cells, the neoplastic myoepithelial cells or their counterparts, in particular, in the majority of the salivary tumors evaluated in the present study may have a potential implication in defining the role of neoplastic myoepithelial cells, believed by many investigators to have a major role in the histomorphology and histogenesis of salivary tumors [9]. As duct-like and /or myoepithelial- like cells are the predominant histopathological features of salivary neoplasms, a subpopulation of ductal cells located on the non-luminal aspect of the striated and excretory ducts of human salivary glands with a more heterogeneous and functionally more complex features have been identified by ultrastructural and immunohistochemical studies [7], which in the present study showed consistent immunoreactivity for MT. These cells termed as the ductal basal cells, their nature and function not fully clear at present, have been suggested to share numerous common immunohistochemical markers with the myoepithelial cells and at least some of the ductal basal cells may serve as the progenitor-reserve cells of salivary gland neoplasms, if not all [7, 8]. However, in salivary tumors, there is no direct evidence for genesis of neoplastic myoepithelial cells either from the myoepithelial cell itself nor from ductal basal cells. Moreover, accumulated evidences of cell 


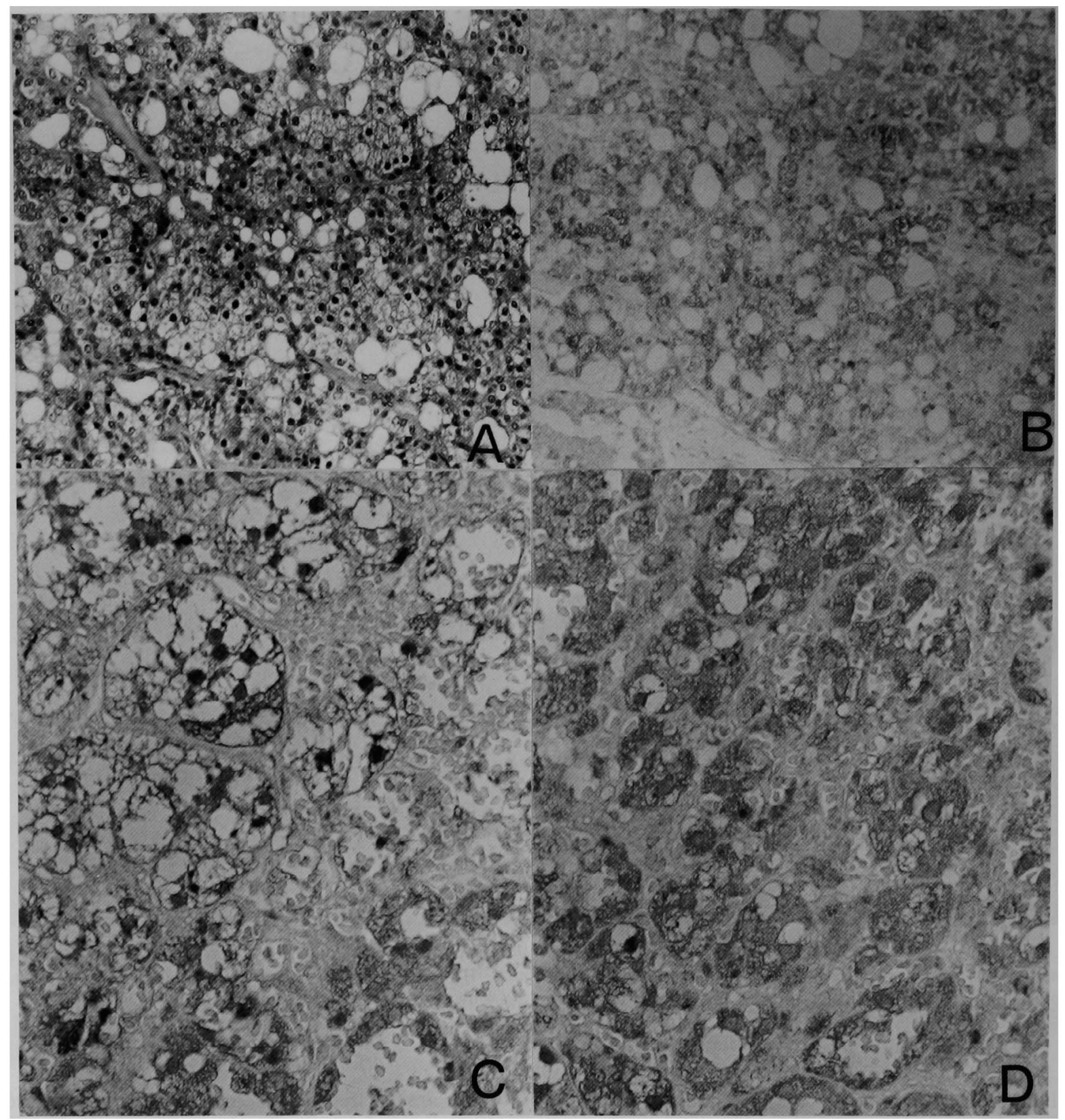

Fig. 7. Acinic cell carcinoma and clear cell carcinoma. $\times 200$. A: Acinic cell carcinoma, HE staining. B: A weak to moderate immunostaining is seen in the tumor cells of acinic cell carcinoma. C \& D: Clear cell carcinoma; Two distinct variation of MT immunostaining is seen in clear cell carcinoma - predominantly nuclear staining of the clear cells without cytoplasmic staining (C) or cytoplasmic staining without nuclear staining (D) except a few cells where both cytoplasmic and nuclear staining are seen in the same specimen.

kinetic studies suggest that all cells in the salivary unit from acini to ductal segments have the potential to proliferate and differentiate/dedifferentiate, and the neoplastic myoepithelial cells in salivary tumors are phenotypic alteration of ductal differentiation or myoepithelial cells or both [10].

The chondroid foci often present in pleomorphic adenoma are the phenotypic alterations of the neoplastic myoepithelial cells and, in addition, the basal cells of
Warthin's tumor, monomorphic adenoma, and subpopulation of cells in adenoid cystic carcinoma, mucoepidermoid carcinoma, papillary cystadenocarcinoma and clear cell carcinoma can be regarded as counterparts of non-luminal cells in salivary gland tumor cells which often present a heterogeneous expression of intermediate filament proteins such as cytokeratins, vimentin, glial fibrillary acidic proteins and other markers as neuron specific enolase and calcium-binding S100 proteins $[7,15-17,27,28,32]$. The 
tumor cells showing immunoreactive MT in the present study, in particular, resembled those cells expressing $\mathrm{S} 100$ proteins. S100 proteins are present either in the nuclei or in the cytoplasm of the non-luminal cells (tumor basal cells) or neoplastic myoepithelial cells of salivary tumors $[16,17]$. S100 proteins are $\mathrm{Ca}^{++}$binding proteins and may regulate the binding of intracellular calcium affecting a number of cellular processes such as secretory functions, cell growth and differentiation. As suggested in earlier studies, the potential of MT to bind essential or toxic metal ions may serve as an intracellular reservoir or sequestration of these metal ions and may have a role in the detoxification or cellular protection against ionizing radiation or acquiring drug resistance to anticancer agents in tumor tissues. The co-expression of immunoreactive MT and calcium binding $\mathrm{S} 100$ proteins in salivary tumor cells, with a more heterogeneous distribution pattern than that of normal salivary tissues, may suggest an existence of a heterogeneous population of tumor cells with differential potential to bind with various metal ions thereby conferring a heterogeneous biological behavior and response to the therapeutic modality of radiation and chemotherapy. In addition, MT, as a metal binding protein, may share at least a number of functional similarity with the calcium binding S100 proteins in normal and neoplastic salivary glands.

This investigation was supported in part by Grantsin-Aid from Japanese Ministry of Education, Science and Culture (No. 07457499)

\section{References}

1. Andrews, G. K., Adamson, E. D. and Gedamu, L.: The ontogeny of expression of murine metallothionein: comparison with the alpha-fetoprotein gene. Dev. Biol. 97: 95-102, 1983.

2. Cherian , M.G.: The significance of the nuclear and cytoplasmic localization of metallothionein in human liver and tumor cells. Environ. Health Perspect. 102: 131-134, 1994.

3. Cherian, M. G. and Goyer, R. A.: Metallothionein and toxicity of metals. Life Sci. 23: 1-10, 1978.

4. Chin, J. L., Banerjee, D., Kadhim, S. A., Kontozoglou, T. E., Chauvin, P. J and Cherian, M. G.: Metallothionein in testicular germ cell tumors and drug resistance. Clinical correlation. Cancer 72: MT29-MT35, 1993.

5. Clarkson. J. P., Elmes, M.E., Jasani, B. and Webb M.: Histologic demonstration of immunoreactive zinc metallothionein in liver and ilium of rat and man. Histochem. J. 17: 343-352, 1985.

6. Danielson, K. G., Ohi, S. and Huang, P. C.: Immunohistochemical detection of metallothionein in specific epithelial cells of rat organs. Proc. Natl. Acad. Sci. USA 79: 2MT1-2MT4, 1982.

7. Dardick, I., Parks, W. R., Little, J. and Brown, D. L.: Characterization of cytoskeletal proteins in basal cells of human parotid gland ducts. Virchows Arch. [A] 412: 525-532, 1988.

8. Dardick, I., Gliniecki, M. R., Jeathcote, J. G., Burford-Mason, A.: Comparative histogenesis and morphogenesis of mucoepidermoid carcinoma and pleomorphic adenoma. An ultrastructural study. Virchows Arch. A 417: 405-417, 1990.
9. Dardick, I., Rippstein, P., Skimming, L., Boivin, M., Parks, W. R. and Dairkee, S. H.: Immunohistochemistry and ultrastructure of myoepithelium and modified myoepithelium of the ducts of human major salivary glands: Histogenetic implications of salivary gland tumors. Oral Surg. Oral Pathol. Oral Med. 64: 703-715, 1987.

10. Dardick, I., Dardick, A. M., MacKay, A. J., Pastolero, G. C., Gullane, P. J. and Burford-Mason, A. P.: Pathology of salivary glands IV. Histogenetic concepts and cycling cells in human parotid and submandibular glands cultured in floating collagen gels. Oral Surg. Oral Pathol. Oral Med. 76: MT7-318, 1993.

11. Douglas-Jones, A. G., Schmid, K. W., Bier, B., Horgan, K., Lyons, K., Dallimore, N. D., Moneypenny, I. J. and Jasani, B.: Metallothionein expression in duct carcinoma in situ of the breast. Hum. Pathol. 26: 217-222, 1995.

12. Kelly, S. M., Basu, A., Teicher, B. A., Hacker, M. P., Hamer, D. H. and Lazo, J. S.: Over expression of metallothionein confers resistance to anticancer drugs. Science 241: 1813-1815, 1988.

13. Kemeny, E., Ivanyi, B., Nemeth, A. and Sonkodi, S.: Application of the immunoperoxidase technique to formalin fixed, paraffin embedded kidney biopsies. Zentral. Allg. Pathol. 128: 119-126, 1983.

14. Kondo, Y., Kuo, S. M., Watkins, S. C. and Lazo, J. S.: Metallothionein localization and cisplatin resistance in human hormone-independent prostatic tumor cell lines. Cancer Res. 55: 474-477, 1995.

15. Mori, M., Tsukitani, K., Ninomiya, T. and Okada, Y.: Various expression of modified myoepithelial cells in salivary pleomorphic adenoma. Immunohistochemical studies. Pathol. Res. Pract. 182: 632-646, 1987.

16. Mori, M., Ninomiya, T., Okada, Y. and Tsukitani, K.: Myoepitheliomas and myoepithelial adenomas of salivary gland origin. Immunohistochemical evaluation of filament proteins, S-100a and b, glial fibrillary acidic proteins, neuron specific enolase and lactoferrein. Pathol. Res. Pract. 184: 168-178, 1989.

17. Mori, M., Yamada, K., Tanaka, T. and Okada, Y.: Multiple expression of keratins, vimentin and S100 protein in pleomorphic salivary adenomas. Virchows Arch. [B] 58: 435-444, 1990.

18. Nakajima, K., Suzuki K., Otaki, N. and Kimura, M: Detection of MT in brain. In "Method in Enzymology, vol 205 Metallochemistry, part B" ed. by J. F. Riordan and B. L. Valle, Academic Press Inc., San Diego, 1991, pp. 387-395.

19. Nartey, N., Cherian, G. and Banerjee, D.: Immunohistochemical localization of Metallothionein in human thyroid tumors. Am. J. Pathol. 129: 177-182, 1987.

20. Nath, R., Kambadur, R., Gulati, S., Paliwal, V. K., Sharma, M.: Molecular aspects, physiological functions, and clinical significance of metallothioneins. Crit Rev. Food Sci. Nutr. 27: 41-85, 1988.

21. Onosaka, S., Min, K. S., Fukura, C., Tanaka, K., Tashiro, S-I, Shimizu, I., Furuta, M., Yasutomi, T., Kobayashi, K. and Yamamoto, K.: Concentration of metallothionein and metal in malignant and non-malignant tissues in human liver. Toxicology 38: 261-268, 1986.

22. Oord, V. D., Sunardhi-Vidyaputra, S. Van Damme, B. and De Ley, M.: Monoclonal antibody to liver metallothionein: a novel marker for myoepithelial cells. Pathol. Res. Pract. 189: 1187-1190, 1993.

23. Riordan, F. R. and Richards, V.: Human fetal liver contains both zinc and copper-binding component in human fetal liver. J. Biol. Chem. 255: 5380-5384, 1980.

24. Ryden, L. and Detusch, H. F.: Preparation and properties of 
the major copper-binding component in human fetal liver. $J$. Biol. Chem. 253: 519-524, 1978.

25. Saika, T., Tsushima, T., Ochi, J., Akebi, N., Nasu, Y., Matsumura, Y., Ohmori, H.: Over-expression of metallothionein and drug-resistance in bladder cancer. Int. J. Urol. 1: 135-139, 1994.

26. Schmid K. W., Ellis, I. O., Gee, J. M. W, Darke, B. M., Lees W. E., Kay, J., Cryer, A., Stark, J. M., Hittmair, A., Ofner, D., Dunser, M., Margretier, R., Daxenbichler, G., Nicholson, R. I., Bier, B., Bocker, W. and Jasani. B.: Presence and possible significance of immunocytochemically demonstratable metallothionein over expression in primary invasive ductal carcinoma of the breast: Virchows Arch. [A] 422: 153-159, 1993.

27. Shrestha, P., Namba, M., Yang, L. J., Oosumi, H. and Mori, M.: Papillary cystadenocarcinoma of salivary glands: an immunohistochemical study. Int. J. Oncol. 4: 587-697, 1994.

28. Shrestha, P., Yang, L. J., Liu, B. L., Namba, M., Qin, C. L., Isono, K., Tsukitani, K. and Mori, M.: Clear cell carcinoma of salivary glands: Immunohistochemical evaluation of clear tumor cells. Anticancer Res. 14: 825-836, 1994.

29. Suzuki, K., Nakajima, K., Kawaharada, U., Uehara, K., Otaki, N., Kimura, M., Fukuda, T. and Takatama, M.: Metallothionein in the human breast. Acta Histochem. Cytochem. 26: 601-607, 1993.
30. Suzuki, T., Suzuki, K., Nakajima, K., Ohma, C., Hayashi, M., Kurokawa, K. and Yamanaka, H.: Immunohistochemical study of cadmium-induced metallothionein in the seminal vesicle coagulating gland, ampullary gland and Cowper's gland of the rat. Acta Histochem. Cytochem. 26: 563-568, 1993.

31. Suzuki, T., Yamanaka, H., Nakajima, K., Suzuki, K., Kanatani, K., Kimura, M., Ohma, C. and Otaki, N.: Immunohistochemical study of metallothionein in human seminal vesicles. Tohoku. J. Exp. Med. 167: 127-134, 1992.

32. Tanaka, N., Hseikh, K-J., Shioda, S., Miyamoto, H., Shinohara, H., Yamada, K., Yuba, R. and Mori, M.: Immunohistochemical and electron microscopic studies on epithelial tumor cells of cystadenolymphomas. Acta Histochem. Cytochem. 24: 181-189, 1991.

33. Thornalley, P. J, and Vasak, M.: Possible role of metallothionein in protection against radiation-induced oxidative stress. Kinetics and mechanism of its reaction with superoxide and hydroxyl radicals. Biochem. Biophys. Acta 827: 36-44, 1985.

34. Umeyama, T., Saruki. K., Imai, K., Yamanaka, H., Suzuki, K., Ikei, N., Kodaira, T., Nakajima, K., Saitoh, H. and Kimura, M.: Immunohistochemical demonstration of metallothionein in the rat. Prostrate 10: 257-264, 1987.

35. Webb., M.: Toxicological significance of metallothionein. Expreintia Suppl. 52 (Metallothionein II); 109-134, 1987. 